\title{
The relationship between low income and household food expenditure patterns in Canada
}

\author{
Sharon Kirkpatrick and Valerie Tarasuk* \\ Department of Nutritional Sciences, Faculty of Medicine, University of Toronto, Toronto, Ontario, Canada M5S 3E2
}

\begin{abstract}
Objectives: To compare food expenditure patterns between low-income households and higher- income households in the Canadian population, and to examine the relationship between food expenditure patterns and the presence or absence of housing payments among low-income households.

Design: Secondary data analysis of the 1996 Family Food Expenditure Survey conducted by Statistics Canada.

Setting: Sociodemographic data and 1-week food expenditure data for 9793 households were analysed.

Subjects: Data were collected from a nationally representative sample drawn through stratified multistage sampling. Low-income households were identified using Statistics Canada's Low Income Measures.

Results: Total food expenditures, expenditures at stores and expenditures in restaurants were lower among low-income households compared with other households. Despite allocating a slightly greater proportion of their food dollars to milk products, low-income households purchased significantly fewer servings of these foods. They also purchased fewer servings of fruits and vegetables than did higher-income households. The effect of low income on milk product purchases persisted when the sample was stratified by education and expenditure patterns were examined in relation to income within strata. Among low-income households, the purchase of milk products and meat and alternatives was significantly lower for households that had to pay rents or mortgages than for those without housing payments.

Conclusions: Our findings indicate that, among Canadian households, access to milk products and fruits and vegetables may be constrained in the context of low incomes. This study highlights the need for greater attention to the affordability of nutritious foods for low-income groups.
\end{abstract}

Studies in several countries have documented incomerelated differences in dietary intake patterns, with those of higher socio-economic status having diets more conducive to good health ${ }^{1-10}$. Despite the paucity of populationbased dietary intake surveys in Canada, considerable nutrition research focusing on low-income groups suggests similar patterns in this country. Qualitative studies have documented the difficulties that families experience in trying to satisfy their food needs within the constraints of limited incomes ${ }^{11-16}$. Dietary intake assessments have revealed substantial levels of nutrient inadequacy ${ }^{17}$, sub-optimal nutrient intakes ${ }^{14,18-22}$ and limited food selection ${ }^{23,24}$ among sub-samples of the lowincome population typically defined by markers of food insecurity. In addition, there is some evidence to suggest that the adoption of healthy eating patterns is complicated for low-income Canadians by the higher costs of some recommended foods ${ }^{25}$.
Although the lack of national intake data hampers the ability to make comparisons between lower- and higherincome groups, analyses of household food expenditure data provide valuable insight into the influence of social and economic conditions on food access and choice within populations ${ }^{26-33}$. In Canada, household food expenditures are monitored through the Family Food Expenditure (FOODEX) Survey, conducted periodically by Statistics Canada ${ }^{34}$. A secondary analysis of data from the 1996 survey, the most recent year for which data are available, was undertaken to compare the food expenditure patterns between low-income and higher-income households, and to examine the relationship between food expenditure patterns and the presence or absence of housing payments among low-income households. The purpose of this comparison was to explore how income affects spending on food as well as the types of food purchased. 


\section{Materials and methods}

\section{Description of the survey}

The 1996 FOODEX Survey sample was selected from the Canadian Labour Force Survey sampling frame through stratified multistage sampling. Data from the FOODEX Survey are representative of the non-institutionalised population of the 10 provinces of Canada, excluding persons living on Indian reserves ${ }^{34}$. The sample was drawn for the whole year and subsequently divided into monthly sub-samples to allow for seasonal variation and other changes during the year ${ }^{34}$. Data collection from households in monthly sub-samples was then spread throughout each month (Dubreuil D, personal communication, Statistics Canada, 2001). Sociodemographic data were collected through an interview with the member of the household who was mainly responsible for its financial maintenance ${ }^{34}$. This reference person was also asked to maintain household expenditure diaries, recording the type, quantity, source (e.g. supermarket, convenience store, speciality store) and price of all food purchased at stores over two consecutive 1 -week periods ${ }^{34}$. Expenditures at stores while away from home overnight or longer and expenditures at restaurants were also recorded, but these food purchases were not described. Similarly, the number of meals served to guests was tracked, but the composition of these meals was not recorded. Respondents estimated the number of meals purchased from restaurants or received free while away from home over the previous month.

\section{Analytical sample}

A preliminary examination of the data and review of Statistics Canada documentation ${ }^{34}$ revealed possible bias in reporting during the second week of data collection. Reported expenditures on food purchased from stores were, on average, $10.9 \%$ lower in the second week compared with the first ${ }^{34}$, and the magnitude of the discrepancy varied with household income. Thus, analyses were restricted to expenditures reported for the first week of data collection. In addition, 1109 households (10.1\%) with no data or incomplete data for key analytical variables were excluded from the analytical sample. This included all households that did not report income or reported zero income, those that reported zero food expenditures or zero food expenditures at stores, and those that completed the interview but not the diary component of the survey. Thus, the analytical sample comprised 9793 of the 10902 households that participated in week one of the survey. A comparison of included versus excluded households suggests that excluded households were more likely to be one-person households, more likely to rent as opposed to own their housing, and more likely to be unemployed (data not shown).

\section{Measures}

The total amount of money spent on food during the week, and the relative proportions spent at stores locally, at restaurants and at stores while away overnight or longer, were calculated for each household. Foods purchased in stores were categorised by Statistics Canada using 200 food $\operatorname{codes}^{34}$. We classified each code into one of the four food groups (i.e. vegetables and fruit, milk products, grain products, and meat and alternatives) or 'other foods' category outlined in Canada's Food Guide to Healthy Eating $^{35}$. Seven aggregate food codes, encompassing foods from more than one food group, could not be classified into one group; on average, these 'miscellaneous' foods accounted for $4.78 \%$ of food expenditures at stores. Expenditures on foods by food group were calculated by summing the amounts spent on each food code within each group. To enable a comparison of the number of servings of the four major food groups purchased across households, the edible quantity of each food was calculated using conversion factors obtained from Agriculture and Agri-Food Canada (Robbins L, personal communication, Agriculture and Agri-Food Canada, 2001) to account for trim and cooking losses. Edible portions were then converted into servings as outlined by Jacobs Starkey et $a l .^{36}$.

\section{Statistical methods}

All statistical analyses were performed using SAS/PC, Version 8.01 (SAS Institute, Cary, NC, USA). Each household in the survey was assigned a weight by Statistics Canada to account for unequal probabilities of selection, nonresponse bias and population demographics; the weighted sample is thus designed to be nationally representative ${ }^{34}$. Because our exclusion of households altered these probabilities, the sample weights were adjusted by dividing the originally assigned weight by the average of the original weights for those households included in the final sample ${ }^{37}$. This procedure accounts for the probability of each household being sampled and results in a weighted sample size of 9793, equal to the number of households in the analytical sample. The procedure was repeated for all analyses in which sub-samples were used.

Low-income households were identified based on the 1996 Low Income Measure (LIM) ${ }^{38}$, a relative measure of low income. The LIM is defined as $50 \%$ of the median adjusted family income; the income adjustment is designed to account for the interrelationship between household needs and household size and composition, as well as economies of scale ${ }^{38}$. The 1996 LIM values range from \$12737 for a single-person household to \$38211 for households with six adults and no children ${ }^{38}$. Based on these LIM values, a dichotomous variable was created to differentiate between low-income households (i.e. households whose reported before-taxes income for the preceding 12 months fell below the LIM), and other households. 


\section{Expenditure patterns among low-income versus other housebolds}

To characterise patterns of food purchasing from stores in relation to household income, we examined food expenditures in each food group, the proportion of the total food expenditures allocated to each food group, and the number of servings of food purchased from the four major food groups. Chi-square tests (PROC FREQ) were conducted to compare the proportions of low-income and other households reporting no expenditure on a particular group of foods. Multiple regression analysis (PROC GLM) was used to examine the relationships between purchasing in each food group and household income level. To account for the skewed nature of these distributions, each in-store purchasing variable was log-transformed prior to analysis, and only households reporting non-zero expenditures in a food group were included in the multiple regression analysis pertaining to that group. Because food expenditures were highly correlated with household size and composition, five variables were included in all regression analyses to account for household differences: the number of persons under 15 years of age; the number of persons 15 to 24 years of age; the number of persons 25 to 64 years of age; the number of persons 65 years of age and greater; and the number of persons for whom no age was specified. The latter variable was necessary to account for Statistics Canada's practice of sometimes suppressing individuals' ages to protect confidentiality of participating households (Wood K, personal communication, Statistics Canada, 2001); $11.07 \%$ of households in our sample included at least one person of unspecified age.

To account for the potentially confounding effects of meals obtained outside the home and meals served to persons who were not members of the household on apparent differences between low-income and other households, the regression of each in-store purchasing variable on the income and household composition variables described above was repeated with the estimated numbers of meals obtained from restaurants, free meals, meals served to guests and expenditures at stores while away overnight or longer included in the model. Seven-day averages were used for each of these variables, but it should be noted that, for some variables, these calculations were based on retrospective accounts of the number of meals obtained over the previous 30 days.

\section{Expenditure patterns among low-income versus other bousebolds stratified by education}

To examine the importance of education on observed income-food expenditure relationships, households were stratified by the educational level of the reference person and the multiple regression models described above were repeated within each stratum. Three education strata were defined: households whose reference person had less than 9 years of education, households whose reference person had at least some secondary school education, and households whose reference person had at least some post-secondary education. While information on spouse's educational attainment was also available, preliminary analysis demonstrated that the reference person's education was an adequate indicator for households where there was a spouse. Only results for the analyses of servings from the major food groups in relation to income level are reported by educational stratum, since analyses of expenditures and proportional allocation of expenditures revealed patterns similar to those observed for the whole sample.

\section{Expenditure patterns of low-income housebolds with or without bousing payments}

Since the LIMs used to identify low-income households are relative rather than absolute measures of poverty, there is considerable variation in the levels of material deprivation experienced by households in this group. Although no quantitative information on households' non-food expenditures or after-tax incomes was available, the presence or absence of housing payments provides an indicator of differences in the funds available for food purchases among the low-income households. In the context of low incomes, high shelter costs can affect food purchasing because shelter is typically considered an inelastic budget item. To examine the relationship between household food expenditure patterns and the availability of funds for food purchases within low-income households, a dichotomous variable was constructed to differentiate households who reported housing payments (i.e. rent or mortgage) from those who owned their housing without a mortgage and thus could be assumed to have no housing payments. Multiple regression analysis was then used to examine the relationship between the presence and absence of housing payments and food expenditure patterns within the low-income subgroup, controlling for household income, size and composition.

\section{Results}

\section{Expenditure patterns among low-income versus otber bousebolds}

Nineteen per cent of the FOODEX sample was identified as low-income. The average income of low-income households was $\$ 13171$, compared with $\$ 54817$ for the other households. A comparison of the sociodemographic profiles of low-income and other households is presented in Table 1. Low-income households had an average size of 2.25 persons, compared with 2.7 persons in other households.

Although there was wide variation in the amount of money households reported spending on food over the 7-day recording period, total food expenditures, expenditures at stores, expenditures at stores while away overnight or longer, and expenditures at restaurants 
Table 1 Selected sociodemographic characteristics of the FOODEX survey sample*

\begin{tabular}{|c|c|c|c|}
\hline Characteristic & $\begin{array}{l}\text { Low-income households } \\
(\%)(n=1937)\end{array}$ & $\begin{array}{l}\text { Other households } \\
(\%)(n=7856)\end{array}$ & $\begin{array}{l}\text { All households } \\
(\%)(n=9793)\end{array}$ \\
\hline \multicolumn{4}{|l|}{ Geographic region } \\
\hline Newfoundland & 2.5 & 1.5 & 1.7 \\
\hline Prince Edward Island & 0.6 & 0.4 & 0.4 \\
\hline Nova Scotia & 3.7 & 3.1 & 3.2 \\
\hline New Brunswick & 3.2 & 2.3 & 2.5 \\
\hline Quebec & 28.5 & 25.6 & 26.1 \\
\hline Ontario & 34.9 & 37.1 & 36.7 \\
\hline Manitoba & 3.6 & 3.7 & 3.6 \\
\hline Saskatchewan & 4.4 & 3.2 & 3.4 \\
\hline Alberta & 6.8 & 9.3 & 8.8 \\
\hline British Columbia & 11.8 & 13.7 & 13.3 \\
\hline Geographic region suppressed $\dagger$ & 0.1 & 0.4 & 0.3 \\
\hline \multicolumn{4}{|l|}{ Household type } \\
\hline One-person households & 42.2 & 18.5 & 22.9 \\
\hline Husband-wife without children & 13.3 & 27.8 & 25.1 \\
\hline Husband-wife with children & 20.0 & 37.7 & 34.4 \\
\hline Husband-wife with others & 2.4 & 4.0 & 3.7 \\
\hline Lone-parent households & 15.9 & 4.9 & 6.9 \\
\hline Other & 6.2 & 7.2 & 7.0 \\
\hline \multicolumn{4}{|l|}{ Housing tenure } \\
\hline Own without mortgage & 25.7 & 32.9 & 31.6 \\
\hline Own with mortgage & 11.4 & 38.4 & 33.4 \\
\hline Rent & 63.0 & 28.7 & 35.0 \\
\hline \multicolumn{4}{|l|}{ Employment status of reference person } \\
\hline Employed & 26.4 & 70.2 & 62.1 \\
\hline Not employed & 69.2 & 26.4 & 34.3 \\
\hline Employment status unknown & 4.4 & 3.4 & 3.6 \\
\hline \multicolumn{4}{|l|}{ Country of birth of reference person } \\
\hline Canada & 75.0 & 80.8 & 79.7 \\
\hline Outside Canada & 18.7 & 15.9 & 16.4 \\
\hline Country of birth unknown & 6.4 & 3.4 & 4.0 \\
\hline \multicolumn{4}{|l|}{ Educational attainment of reference person } \\
\hline Less than 9 years of education & 27.8 & 9.2 & 12.6 \\
\hline Some/completed secondary school & 44.0 & 38.3 & 39.3 \\
\hline Some/completed post-secondary education & 28.0 & 52.4 & 47.9 \\
\hline Educational attainment unknown & 0.3 & 0.2 & 0.2 \\
\hline
\end{tabular}

* Figures in this table have been weighted using an adjusted weight, obtained by dividing the originally assigned weight by the average of the original weights for those households included in the final sample. The weighted sample is designed to be nationally representative.

†The geographic region of a small percentage of households has been suppressed by Statistics Canada to protect the confidentiality of these households.

were generally lower among low-income households than among other households (Table 2). Of the dollars lowincome households spent on food, 83.52\% (standard deviation (SD) \pm 22.87 ) were on in-store purchases, whereas in-store purchases represented only $73.29 \%$ (SD \pm 24.73 ) of the total spending among other households. This difference was statistically significant, even when differences in household size and composition were taken into account $(F$-value $=263.71, \mathrm{df}=1, P<0.0001)$.
A more detailed examination of in-store expenditures revealed that low-income households were more likely than other households to report zero expenditure on each of the food groups assessed (Table 3). Among those who did report expenditures, low-income households spent significantly less than other households, but allocated a slightly greater proportion of their food dollars to milk products and grain products (Table 4). When the amounts of food purchased were compared, low-income

Table 2 Total food expenditures, expenditures at stores and expenditures at restaurants reported by low-income and other households over 7 days

\begin{tabular}{|c|c|c|}
\hline & \multicolumn{2}{|c|}{ Expenditure $(\$)$, weighted mean \pm standard deviation (median) } \\
\hline & $\begin{array}{l}\text { Low-income households } \\
\qquad(n=1937)\end{array}$ & $\begin{array}{l}\text { Other households } \\
\qquad(n=7856)\end{array}$ \\
\hline Total food expenditure & $80.37 \pm 72.16(62.66)$ & $134.52 \pm 92.28(116.25)$ \\
\hline Expenditures in stores & $65.02 \pm 58.68(50.43)$ & $95.02 \pm 69.03(81.86)$ \\
\hline $\begin{array}{l}\text { Expenditures in stores while away } \\
\text { from home overnight or longer }\end{array}$ & $0.36 \pm 2.81(0.00)$ & $1.33 \pm 7.52(0.00)$ \\
\hline Expenditures in restaurants & $14.99 \pm 34.27(1.89)$ & $38.17 \pm 52.34(22.61)$ \\
\hline
\end{tabular}


Table 3 Comparison of purchased servings of vegetables and fruit, milk products, meat and alternatives and grain products between low-income and other households who reported some purchase of these foods over 7 days

\begin{tabular}{lcccccc}
\hline & \multicolumn{2}{c}{$\begin{array}{c}\text { Percentage reporting any } \\
\text { expenditure in food group }\end{array}$} & & \multicolumn{2}{c}{$\begin{array}{c}\text { Mean servings } \pm \text { standard } \\
\text { errort }\end{array}$} \\
\cline { 2 - 3 } \cline { 6 - 7 } Food group & $\begin{array}{c}\text { Low-income households } \\
(n=1937)\end{array}$ & $\begin{array}{c}\text { Other households } \\
(n=7856)\end{array}$ & & $\begin{array}{c}\text { Low-income } \\
\text { households }\end{array}$ & $\begin{array}{c}\text { Other } \\
\text { households }\end{array}$ \\
\hline Vegetables and fruit & 85.97 & 92.12 & & $59.61 \pm 1.03 \ddagger$ & $66.38 \pm 1.01$ \\
Milk products & 87.72 & 92.00 & & $26.30 \pm 1.02 \ddagger$ & $30.93 \pm 1.01$ \\
Meat and alternatives & 83.11 & 88.92 & & $32.89 \pm 1.03$ & $34.64 \pm 1.01$ \\
Grain products & 83.34 & 89.59 & & $83.80 \pm 1.03$ & $82.18 \pm 1.01$ \\
\hline
\end{tabular}

${ }^{*}$ Chi-square tests $(\mathrm{df}=1)$ indicate that differences between proportions reporting non-zero expenditures in each income group are significant at $P<0.0001$ for all food groups.

†Least-square means and standard errors are the anti-logs of estimates from single-equation weighted regression models (PROC GLM) in which the log-transformed number of servings for each food group was regressed on lowincome indicator and household composition variables to account for number and ages of persons in household. Only households reporting some expenditure in a food group were included in the analysis for that food group.

$\ddagger$ Indicates significant $(P<0.05)$ difference between income groups, based on the regression model described above.

Table 4 Comparison of expenditures on and proportional allocation of expenditures to vegetables and fruit, milk products, meat and alternatives, grain products, other foods and miscellaneous foods between low-income and other households who reported some purchase of these foods over 7 days*

\begin{tabular}{|c|c|c|c|c|}
\hline \multirow[b]{2}{*}{ Food group } & \multicolumn{2}{|c|}{ Expenditure $(\$)$, mean \pm standard error† } & \multicolumn{2}{|c|}{$\begin{array}{c}\text { Allocation }(\%) \text { of expenditures, } \\
\text { mean } \pm \text { standard errort }\end{array}$} \\
\hline & Low-income households & Other households & $\begin{array}{l}\text { Low-income } \\
\text { households }\end{array}$ & $\begin{array}{l}\text { Other } \\
\text { households }\end{array}$ \\
\hline Vegetables and fruit & $11.92 \pm 1.02 \ddagger$ & $13.91 \pm 1.01$ & $18.61 \pm 1.02$ & $18.00 \pm 1.01$ \\
\hline Milk products & $8.27 \pm 1.02 \ddagger$ & $10.22 \pm 1.01$ & $14.32 \pm 1.02 \ddagger$ & $13.61 \pm 1.01$ \\
\hline Meat and alternatives & $15.57 \pm 1.03 \ddagger$ & $18.50 \pm 1.01$ & $23.38 \pm 1.02$ & $22.81 \pm 1.01$ \\
\hline Grain products & $7.02 \pm 1.02 \ddagger$ & $7.87 \pm 1.01$ & $11.16 \pm 1.02 \ddagger$ & $10.14 \pm 1.01$ \\
\hline Other foods & $13.17 \pm 1.02 \ddagger$ & $16.65 \pm 1.01$ & $21.25 \pm 1.02$ & $21.85 \pm 1.01$ \\
\hline Miscellaneous foods & $4.70 \pm 1.04 \ddagger$ & $5.67 \pm 1.01$ & $5.83 \pm 1.03$ & $5.99 \pm 1.01$ \\
\hline
\end{tabular}

* Proportions of sample subgroups included in each analysis are same as those presented in Table 3.

$\dagger$ Least-square means and standard errors presented here are the anti-logs of estimates from single-equation weighted regression models in which log-transformed expenditure or \% allocation was regressed on the low-income indicator and household composition variables to account for number and ages of persons in household.

$\ddagger$ Indicates significant $(P<0.05)$ difference between income groups.

households appeared to purchase significantly fewer servings of vegetables and fruit and milk products in comparison to higher-income households (Table 3). Subsequent examination of specific product subgroups within the milk group indicated that the observed differences between low-income and other households were not accounted for by differences in the reported purchase of higher-cost dairy products; fluid milk purchases were also significantly lower among lowincome households (data not shown). No significant differences were detected in the number of servings of meat and alternatives or grain products purchased (Table 3). Controlling for the reported number of meals purchased from restaurants, received free and served to guests, and for expenditures at stores while away from home overnight or longer, caused the difference in servings of meat and alternatives between low-income and other households to become statistically significant but otherwise did not change the direction or significance of the findings presented here.

\section{Expenditure patterns among low-income versus other bousebolds stratified by education}

When household food expenditure patterns between low-income and other households were compared within strata defined by the reference person's education level, low-income households purchased fewer servings of milk products compared with other households across all three strata (Table 5). In addition, among households whose reference person had secondary schooling, those with low incomes purchased fewer servings of vegetables and fruit and meat and alternatives than their higher-income counterparts (Table 5).

\section{Expenditure patterns of low-income bousebolds witb or without bousing payments}

Among low-income households, those with housing payments in the form of mortgages or rent spent significantly less on food in total and less on food at stores, although spending at stores while away from home overnight or longer and at restaurants did not differ 
between the groups (data not shown). Households with housing payments were more likely than households without payments to report no expenditures in each of the food groups examined here (Table 6). Among households that did report purchases in a specific food group, those with housing payments spent significantly less on foods in the milk products and meat and alternatives (data not shown) and purchased significantly fewer servings of food in these categories (Table 6). No differences were detected in total expenditures or servings purchased of vegetables and fruit and grain products. There were no discernible differences in how the food dollar was allocated (data not shown).

\section{Discussion}

The foregoing analyses revealed systematic differences in the food expenditure patterns of low-income households compared with other households in the Canadian population. While it is not surprising that households with lower incomes would spend less money on food (at restaurants and at stores), it is of concern that they purchased significantly fewer servings of fruits and vegetables and milk products than did higher-income households. Differences in food purchasing patterns between low- and higher-income households persisted when the sample was stratified by the reference person's education level, indicating that low income affects food expenditures across the educational spectrum. Food expenditures in low-income households were further constrained if some proportion of household income had to be allocated for rent or mortgage payments, highlighting the impact of additional financial constraints on the amount and selection of foods available for consumption in these households.

Our finding of no discernible differences in the quantities of some food groups purchased by low-income compared with higher-income households could be interpreted as evidence that lower-income households are able to maintain or increase their purchasing efficiency for some food groups, such as meat and alternatives and grain products, more than others. Similarly, Horton and Campbell $^{27}$ noted, based on an analysis of data from the 1984 FOODEX survey, that low-income households are more likely to buy more economical brands of a particular food item, and thus spend their food dollars as efficiently as possible. Nevertheless, when fewer dollars are available for food purchases, constraints on food selection may lead to the purchase of less nutritionally desirable foods in instances where better products are sold at higher prices. This concern is exemplified in a Canadian study indicating that foods promoted as good for heart health were more expensive than other foods ${ }^{25}$.

Interestingly, our findings indicate that, in Canadian households, purchases of milk products are particularly affected by low income. This relationship persisted across 
Table 6 Comparison of purchased servings of vegetables and fruit, milk products, meat and alternatives, grain products and other foods among low-income households with and without housing payments households who reported some purchase of these foods over 7 days

\begin{tabular}{|c|c|c|c|c|}
\hline \multirow[b]{2}{*}{ Food group } & \multicolumn{2}{|c|}{$\begin{array}{l}\text { Percentage reporting any } \\
\text { expenditure in food group* }\end{array}$} & \multicolumn{2}{|c|}{ Mean servings \pm standard error $\dagger$} \\
\hline & $\begin{array}{l}\text { Households } \\
\text { with housing } \\
\text { payments } \\
(n=1440)\end{array}$ & $\begin{array}{l}\text { Households } \\
\text { with no housing } \\
\text { payments } \\
(n=497)\end{array}$ & $\begin{array}{l}\text { Households } \\
\text { with housing } \\
\text { payments }\end{array}$ & $\begin{array}{l}\text { Households } \\
\text { with no housing } \\
\text { payments }\end{array}$ \\
\hline Vegetables and fruit & 84.78 & 89.40 & $50.08 \pm 1.03$ & $52.09 \pm 1.06$ \\
\hline Milk products & 86.64 & 90.85 & $21.68 \pm 1.02 \ddagger$ & $27.36 \pm 1.05$ \\
\hline Meat and alternatives & 81.61 & 87.45 & $26.39 \pm 1.03 \ddagger$ & $30.85 \pm 1.05$ \\
\hline Grain products & 81.88 & 87.55 & $70.83 \pm 1.03$ & $79.40 \pm 1.05$ \\
\hline
\end{tabular}

${ }^{*}$ Chi-square tests $(\mathrm{df}=1)$ indicate that differences between proportions in subgroups defined by housing tenure are all significant at $P<0.0001$.

† Least-square means and standard errors are the anti-logs of estimates for groups defined by housing status, derived from single-equation weighted regression models (PROC GLM) in which the log-transformed number of servings from each food group was regressed on 12-month household income before taxes, housing tenure and household composition variables to account for number and ages of persons in household. Only households reporting some expenditure in a food group were included in the analysis for that food group.

$\ddagger$ Indicates significant $(P<0.05)$ difference between groups defined by housing tenure, based on regression model described above.

educational strata and within the low-income subgroup when we examined expenditures in relation to the presence or absence of housing payments. The relationship also persisted when subgroups of the milk products group were analysed. Furthermore, low-income households purchased fewer servings of milk products despite allocating a slightly greater proportion of their total expenditure to this food group. This suggests that lowincome households place no less priority than do others on the consumption of foods from this group. Rather, it would appear that milk product purchasing is particularly sensitive to household economics. In the absence of data on household food use, foods purchased at restaurants, cafeterias and fast-food outlets, and intra-household food distribution during the week for which food expenditures were analysed, it is impossible to assess the nutrient adequacy of the available food for individuals within the sample households. None the less, in the light of current recommendations for individuals to maintain relatively high levels of calcium intake across the life cycle ${ }^{39}$, income-related compromises in the purchase of milk products are a matter of public health concern.

The direction of our findings is consistent with the results of Canadian studies in which individuals' food intakes have been assessed. Dubois and Girard $^{40}$ documented strong social gradients in reported calcium intake among women and men in the Quebec Nutrition Survey. Similarly, Ghadirian and Shatenstein ${ }^{41}$ reported that low calcium intake was related to low income among Montreal women. Dietary intake assessments conducted with a number of smaller low-income samples have documented similar concerns. For example, Badun et al. ${ }^{18}$ concluded that parents in a low-income community in Ontario had low intakes of calcium, iron, zinc, vitamin A and folate. Furthermore, Evers and Hooper $^{20}$ found that children in low-income Ontario communities may be at risk for inadequate intakes of calcium and vitamin A, while McIntyre et $a l .{ }^{14}$ found that a sample of low-income women and children in the Atlantic provinces had low intakes of calcium, vitamin A, vitamin D and folate. A study of women in families using food banks in Toronto documented very low levels of calcium intake ${ }^{17}$ and limited consumption of milk products ${ }^{24}$, while Jacobs Starkey et al. ${ }^{22}$ found low levels of calcium, vitamin A and zinc among food bank users in Montreal. The authors also found that their sample consumed fewer servings of milk products than did Quebecers in general ${ }^{23}$.

A potential source of bias in our data was the application of standard factors to adjust for food waste in the conversion of expenditure data to edible food servings. Insofar as cooking, trim and plate wastes vary with income, we may have systematically underestimated the number of servings of foods, particularly meat and alternatives and vegetables and fruit, purchased by lowincome households. Estimated purchases of milk and grain products would be much less affected, however, because there is typically very little waste associated with the use of these foods.

A second potential source of bias in the foregoing analyses is that we considered only food purchased for use in the home, not foods obtained and consumed outside the home. While we attempted to control for the number of meals obtained from restaurants, it must be noted that this number included a value for meals obtained while away from home or overnight that was not a recorded value but was estimated based on patterns over the previous month. However, it is unlikely that a more exact estimate of this parameter would have changed our findings given the differences in expenditures at stores and at restaurants. Further, others have noted that foods eaten away from home tend to be high in nutrients that are already present in the diet in high quantities (e.g. fat or 
sodium) rather than nutrients more commonly underrepresented in the diet (e.g. calcium or iron) $)^{40,42,43}$. Thus, it is unlikely that the lower numbers of servings of fruits and vegetables and milk products apparent in the food purchases of low-income households were compensated for by a greater consumption of these foods outside the home.

Although we were able to control for the reported number of meals received free of charge in our analyses, no attempt was made in FOODEX to quantify the amount of food some households might have received from food banks or other charitable food assistance programmes. However, in any one month, only $2-3 \%$ of Canadians receive food from food banks, and they are unlikely to receive more than a 3 - or 4-day supply of food ${ }^{44}$. Thus, the omission of this source of food is unlikely to have been a major source of bias in the analyses presented here. Finally, although our exclusion criteria caused us to exclude $10 \%$ of the original sample, the known characteristics of this group do not suggest that their omission biased the results.

In summary, the income-related differences in food expenditure patterns revealed through this study suggest that access to milk products and fruits and vegetables may be constrained in the context of low incomes. These findings point to the critical need for better monitoring and interventions to ensure the affordability of nutritious foods for low-income Canadians.

\section{Acknowledgements}

This research was supported by funding from the Danone Institute of Canada. The authors wish to thank Linda Robbins from Agriculture and Agri-Food Canada for sharing her work in converting purchased quantities of foods to edible quantities. The authors also wish to thank the DLI unit of Statistics Canada for their assistance in obtaining the microdata files.

\section{References}

1 Bolton-Smith C, Smith WCS, Woodward M, TunstallPedoe H. Nutrient intakes of different social-class groups: results from the Scottish Heart Health Study (SHHS). British Journal of Nutrition 1990; 65: 321-35.

2 Braddon FEM, Wadsworth MEJ, Davies JMC, Cripps HA Social and regional differences in food and alcohol consumption and their measurement in a national birth cohort. Journal of Epidemiology and Community Health 1988; 42: 341-9.

3 Davey Smith G, Brunner E. Socio-economic differentials in health: the role of nutrition. Proceedings of the Nutrition Society 1997; 56: 75-90.

4 Hupkens CLH, Knibbe RA, Drop MJ. Social class differences in women's fat and fibre consumption: a cross-national study. Appetite 1997; 28: 131-49.

5 James WP, Nelson M, Ralph A, Leather S. The contribution of nutrition to inequalities in health. British Medical Journal 1997; 314: 1545-9.
6 Krebs-Smith SM, Cook A, Subar AF, Cleveland L, Friday J. US adults' fruit and vegetable intakes, 1989-1991: a revised baseline for the Healthy People 2000 objective. American Journal of Public Health 1995; 85: 1623-9.

7 Patterson B, Block G, Rosenberger W, Pee D, Kahle LL. Fruit and vegetables in the American diet: data from NHANES II survey. American Journal of Public Health 1990; 80: 1443-9.

8 Popkin BM, Siega-Riz AM, Haines PS. A comparison of dietary trends among racial and socioeconomic groups in the United States. New England Journal of Medicine 1996; 335: 716-20.

9 Pryer J, Brunner E, Elliott $\mathrm{P}$, Nichols R, Dimond $\mathrm{H}$, Marmot M. Who complied with COMA 1984 dietary fat recommendations among a nationally representative sample of British adults in 1986-7 and what did they eat? European Journal of Clinical Nutrition 1995; 49: $718-28$.

10 Smith AM, Baghurst KI. Public health implications of dietary differences between social status and occupational category groups. Journal of Epidemiology and Community Health 1992; 46: 409-16.

11 Hamelin AM, Beaudry M, Habicht JP. La vulnerabilite des menages a l'insecurite alimentaire. Revue Canadienne D'etudes du Developpement 1998; 19: 277-306.

12 Hamelin AM, Habicht JP, Beaudry M. Food insecurity: consequences for the household and broader social implications. Journal of Nutrition 1999; 129: 525S-8S.

13 Hamelin AM, Beaudry M, Habicht JP. Characterization of household food insecurity in Quebec: food and feelings. Social Science \& Medicine 2002; 54: 119-32.

14 McIntyre L, Raine K, Glanville T, Dayle J, Workman T, Anderson B, et al. Hungry Mothers of Barely Fed Children: A Summary Report of a CIHR/NHDRP Project on the Diets and Food Experiences of Low-income Lone Mothers in Atlantic Canada in Relation to their Children. Halifax, Nova Scotia: Dalhousie University, 2001.

15 Tarasuk V, Maclean $\mathrm{H}$. The food problems of low-income single mothers: an ethnographic study. Canadian Home Economics Journal 1990; 40(2): 76-82.

16 Travers KD. The social organization of nutritional inequities. Social Science \& Medicine 1996; 43: 543-53.

17 Tarasuk VS, Beaton GH. Women's dietary intakes in the context of household food insecurity. Journal of Nutrition 1999; 129: 672-9.

18 Badun C, Evers SE, Hooper M. Food security and nutritional concerns of parents in an economically disadvantaged community. Journal of the Canadian Dietetic Association 1995; 56: 75-80.

19 Doran L, Evers S. Energy and nutrient inadequacies in the diets of low-income women who breast-feed. Journal of the American Dietetic Association 1997; 97: 1283-7.

20 Evers SE, Hooper MD. Dietary intake and anthropometric status of 7 to 9 year old children in economically disadvantaged communities in Ontario. Journal of the American College of Nutrition 1995; 14(6): 595-603.

21 Jacobs Starkey L, Kuhnlein H, Gray-Donald K. Food bank users: sociodemographic and nutritional characteristics. Canadian Medical Association Journal 1998; 158(9): 1143-9.

22 Jacobs Starkey L, Gray-Donald K, Kuhnlein HV. Nutrient intake of food bank users is related to frequency of food bank use, household size, smoking, education and country of birth. Journal of Nutrition 1999; 129: $883-9$

23 Jacobs Starkey L, Kuhnlein HV. Montreal food bank users' intakes compared with recommendations of Canada's Food Guide to Healthy Eating. Canadian Journal of Dietetic Practice and Research 2000; 61: 73-5. 
24 Tarasuk VS. Household food insecurity with hunger is associated with women's food intakes, health, and household circumstances. Journal of Nutrition 2001; 131: 2670-6.

25 Travers KD. Availability and cost of heart healthy diet changes in Nova Scotia. Journal of the Canadian Dietetic Association 1997; 58: 176-83.

26 Campbell CC, Horton SE. Apparent nutrient intakes of Canadians: continuing nutritional challenges for public health professionals. Canadian Journal of Public Health 1991; 82: 374-80.

27 Horton S, Campbell C. Do the poor pay more for food? Food Market Commentary 1990; 11: 33-9.

28 Horton S, Campbell C. Wife's employment, food expenditures, and apparent nutrient intake: evidence from Canada. American Journal of Agricultural Economics 1991; 73: $784-94$.

29 Horton SE, Campbell CC. Regional variations in apparent nutrient intake in urban Canada. Journal of the Canadian Dietetic Association 1992; 53: 19-23.

30 Hunt L. Socioeconomic profile and food expenditures of the single-parent family in Canada, 1974-1982. Food Market Commentary 1985; 7(4): 55-63.

31 Simeon DT, Patterson AW. Use of food expenditure data to estimate household nutrient accessibility. West Indian Medical Journal 1996; 45: 25-7.

32 Trichopoulou A, Kanellou A, Lagiou P, Zintzaras E, and the DAFNE I Group. Integration of nutritional data based on household budget surveys in European countries. Proceedings of the Nutrition Society 1996; 55: 699-704.

33 Upton PK, Gibney MJ. Nutrient intakes in Ireland in 1980: estimates derived from household expenditure on food. Irish Journal of Medical Science 1987; 156(3): 83-9.

34 Statistics Canada Income Statistics Division. 1996 Food Expenditure Survey Public-use Microdata Files, Version 1. Ottawa, Ontario: Statistics Canada, 1999.

35 Health and Welfare Canada. Canada's Food Guide to
Healthy Eating. Ottawa, Ontario: Supply and Services Canada, 1992.

36 Jacobs Starkey L, Johnson-Down L, Gray-Donald K. Food habits of Canadians: comparison of intakes in adults and adolescents to Canada's Food Guide to Healthy Eating. Canadian Journal of Dietetic Practice and Research 2000; 62: $61-9$.

37 Goel V. Analysis of complex surveys. Toronto, Ontario: Institute for Clinical Evaluative Sciences, 1993 [unpublished].

38 Statistics Canada Income Statistics Division. Low Income Cutoffs from 1990 to 1999 and Low Income Measures from 1989 to 1998. Catalogue No. 75F0002MIE-00017. Ottawa, Ontario: Statistics Canada, 2001.

39 Institute of Medicine. Dietary Reference Intakes for Calcium, Phosphorus, Magnesium, Vitamin D, and Fluoride. Washington, DC: National Academy Press, 1997.

40 Dubois L, Girard M. Social position and nutrition: a gradient relationship in Canada and the USA. European Journal of Clinical Nutrition 2001; 55: 366-73.

41 Ghadirian P, Shatenstein B. Nutrient patterns, nutritional adequacy, and comparisons with nutrition recommendations among French-Canadian adults in Montreal. Journal of the American College of Nutrition 1996; 15: 255-63.

42 Lin B, Guthrie J, Frazão E. Nutrient contribution of food away from home. In: Frazão E, ed. America's Eating Habits: Changes \& Consequences. Agriculture Information Bulletin No. 750. Washington, DC: Economic Research Service, United States Department of Agriculture, 1999; 217-39.

43 Guthrie JF, Lin B, Frazão E. Role of food prepared away from home in the American diet, 1977-78 versus 1994-96: changes and consequences. Journal of Nutrition Education and Behavior 2002; 341: 40-150.

44 Wilson B, Steinman C. HungerCount 2000: A Surplus of Hunger. Toronto, Ontario: Canadian Association of Food Banks, 2000. 